\title{
ILUMINAÇÃO NATURAL EM EDIFíCIOS DE ESCRITÓRIOS: AVALIAÇÃO DINÂMICA DE DESEMPENHO PARA SÃO PAULO
}

\section{DAYLIGHT PERFORMANCE OF OFFICE BUILDINGS: A DYNAMIC EVALUATION FOR THE CASE OF SÃO PAULO}

\author{
Mônica Pereira Marcondes Cavaleri 1 \\ Faculdade de Arquitetura e Urbanismo da Universidade de São Paulo, São Paulo, SP, Brasil, marcondesmo@gmail.com \\ Guilherme Reis Muri Cunha ${ }^{2}$ \\ Faculdade de Arquitetura e Urbanismo da Universidade de São Paulo, São Paulo, SP, Brasil, guilherme.reis.cunha@usp.br \\ Joana Carla Soares Gonçalves ${ }^{3}$ \\ Faculdade de Arquitetura e Urbanismo da Universidade de São Paulo, São Paulo, SP, Brasil, jocarch@usp.br
}

\begin{abstract}
Resumo
A revisão dos critérios definidores de conforto visual e o teste de novos métodos de avaliação da iluminação natural de edifícios, com base no clima, vem sendo realizados na última década. Nesse contexto, o principal objetivo deste trabalho é analisar o desempenho da luz natural em um edifício de escritórios de planta profunda representativo da produção recente na cidade de São Paulo, por meio de simulações dinâmicas com base em dados climáticos para a definição da zona passiva de iluminação natural em diferentes orientações, com e sem proteções solares. O edifício foi modelado no programa Rhinoceros-5 e as avaliações de desempenho foram realizadas no plug-in Diva-for-Rhino. Partiu-se de 75\% de UDI como critério, com duas faixas de iluminâncias: UDI300-3000 e UDI100-3000, que foram comparadas ao desempenho com base em um valor mínimo de 500 lux. Complementarmente, realizaramse simulações para dois dias típicos do clima local: inverno e verão, para quantificar níveis de iluminância no espaço ao longo do dia e, assim, adicionar outra medida de qualidade. Os resultados indicaram dificuldade para obter 75\% de UDI na área total do escritório; evidenciaram a maior influência do sombreamento externo na periferia da planta; e quantificaram os efeitos de redução de níveis luminosos excessivos nessa porção do ambiente em função do sombreamento. Potenciais zonas passivas foram indicadas para os casos e condições específicos deste estudo, variando de 3,5 a 12,0 metros. Conclui-se que o critério ampliado de 100 lux a 3.000 lux é aplicável, num contexto onde requer-se qualidade arquitetônica e diversidade ambiental.
\end{abstract}

Palavras-chave: Iluminação natural. Edifício de escritórios. Clima subtropical. Avaliação dinâmica.

\begin{abstract}
A review of visual comfort criteria and daylight analysis supported by newer assessment methods involving climatic-based evaluations have been investigated in the last decade. In this context, the main objective of this research work is to analyze the daylighting performance of the deep-plan office building, representative of the recent building production in the city of São Paulo, using climatebased computer simulations performed to the definition of the daylight passive zone of the base-case. The digital model was developed in the software Rhinoceros-5 and the performance assessment with the use of the plug-in Diva-for-Rhino. The initial criterion was a UDI factor of 75\% for two illuminance ranges: UDI300-3000 e UDI100-3000; from which the results were compared against the Daylight Autonomy target of 500 lux. In addition to that, simulations were carried out for the recording of illuminance levels in two typical days of the São Paulo climate: winter and summer, to quantify the illuminance levels in the space throughout the day and therefore, add another measurement of quality. The results pointed out the difficulty in achieving a UDI of 75\% across the whole office floor; made evident the more significant influence of external shading in the periphery of the plan, and quantified the reduction effects of excessive illuminance levels in the same periphery. Potential passive zones were established for the specific conditions of the study, varying significantly between 3.5 and 12.0 meters. Moreover, the wider range between 100lux and $3.000 l u x$ is applicable when architectural diversity is required.
\end{abstract}

Keywords: Daylight performance. Office building. Subtropical climate. Climate-based evaluation. Dynamic evaluation..

How to cite this article:

MARCONDES CAVALERI, Mônica Pereira; CUNHA, Guilherme Reis Muri; GONÇALVES, Joana Carla Soares. Iluminação natural em edifícios de escritórios: avaliação dinâmica de desempenho para São Paulo. PARC Pesquisa em Arquitetura e Construção, Campinas, SP, v. 9, n. 1, p.19-34, mar. 2018. ISSN 1980-6809. Disponível em: <https://periodicos.sbu.unicamp.br/ojs/index.php/parc/article/view/8650725>. Acesso em: 09 maio 2018. doi:https://doi.org/10.20396/parc.v9i1.8650725 


\section{Introdução}

$\mathrm{Na}$ última década, tem-se destacado no campo científico internacional a validade e a necessidade de reavaliação dos estudos de iluminação natural dos edifícios, tendo em vista a definição ou a seleção de critérios para melhor classificar o conforto visual dos ocupantes. Paralelamente à discussão sobre critérios, vem sendo explorada a utilização de métodos de avaliação de iluminação natural baseados em dados anuais de clima (NABIL; MARDALJEVIC, 2006; REINHART; WIENOLD, 2001; MARDALJEVIC et al., 2012; ANDERSEN, 2015).

Diante do dinamismo e da complexidade da interação do homem com o ambiente, a avaliação de iluminação natural de um espaço passa a ser abordada sob dois enfoques distintos: o primeiro deles compreende os aspectos visuais ou de conforto, e o segundo aborda os aspectos não visuais do campo das ciências fotobiológicas ou de saúde (ANDERSEN, 2015). Os aspectos de conforto estão relacionados com o desempenho do ocupante na execução de tarefas e ao seu bem-estar com o ambiente; já os aspectos de saúde aparecem atrelados aos ciclos circadianos das pessoas e consideram o papel da luz natural no controle de inúmeros processos bioquímicos do corpo, essenciais para a saúde humana (ANDERSEN, 2015; MARDALJEVIC et al., 2012).

Nesse contexto, o interesse deste trabalho está na forma de avaliação da iluminação natural em edifícios com base em dados anuais de clima, e nos aspectos de conforto.

A adoção da simulação anual de iluminação natural dinâmica, também chamada em inglês: Climate-Based Daylight Modelling (CBDM), tem ganhado destaque na discussão sobre métodos para a avaliação da iluminação natural em edifícios, no cenário internacional, aparecendo como alternativa aos métodos e critérios estáticos de avaliação, característicos das décadas anteriores. As avaliações estáticas, chamadas em inglês de one point in time, objetivam primordialmente $\mathrm{o}$ indicador de desempenho Daylight Factor ${ }^{(1)}$ ou, em português: Fator de Luz Diurna - FLD (DIDONÉ; PEREIRA, 2010; REINHART; MARDALJEVIC; ROGERS, 2006).

De modo análogo às avaliações termodinâmicas, as avaliações dinâmicas de iluminação natural de edifícios geram uma série temporal de predições por ponto de estudo, geralmente anuais e horárias. $\mathrm{O}$ aspecto inovador desse tipo de avaliação é a utilização de dados climáticos contendo condições reais de céu e de sol nas simulações. Desse modo, os resultados obtidos nas simulações incluem condições extremas de iluminação que ocorrem nos ambientes de edifícios submetidos a um céu real (MARDALJEVIC et al., 2012), além de variações diárias e sazonais.
As considerações da localização geográfica, de condições reais de céu e, consequentemente, do ingresso de luz direta, permitem uma análise individual de cada orientação ou fachada do edifício. Tais aspectos não são contemplados pelos métodos estáticos mencionados anteriormente.

Os resultados das simulações anuais baseadas em dados climáticos podem ser avaliados tanto em termos de frequência de ocorrência como em valores absolutos de iluminância ou luminância.

Entretanto, no que tange ao desempenho luminoso de uma edificação, o estudo de referências bibliográficas revela que não existe um consenso sobre os indicadores e critérios aceitáveis ou adequados. Como parte dos parâmetros mais comumente encontrados na literatura recente para avaliações dinâmicas de iluminação natural, menciona-se o Daylight Autonomy (DA), o Spatial Daylight Autonomy (sDA), o Annual Sunlight Exposure (ASE), e o Useful Daylight Illuminance (UDI).

O Daylight Autonomy, ou DA, apareceu originalmente em 1989 em uma norma da organização Internacional Association Suissedes Electriciens, e foi redefinido por Reinhart e Walkenhorst em 2001 (REINHART; MARDALJEVIC; ROGERS, 2006). O DA representa a frequência ao longo do ano com que um dado valor de iluminância é alcançado no plano de trabalho. Para tanto, é estabelecido um valor mínimo de iluminância (por exemplo, 300 lux ou 500 lux) a ser proporcionado no ambiente em questão. Pressupõe-se que a iluminação artificial não será necessária durante a porcentagem de horas do ano em que o ambiente dispõe de no mínimo esse valor pré-determinado.

O Spatial Daylight Autonomy, ou sDA, e o Annual Sunlight Exposure, ou ASE, foram propostos em 2012 pela Illuminating Engineering Society of North America (IESNA, 2012) como parte de um método para avaliação do desempenho luminoso de um edifício ao longo de um ano. Esse método é apresentado no protocolo IES LM-8312 e tem base em dois critérios: o primeiro, relativo ao desempenho da iluminação natural - sDA, e o segundo, relativo ao conforto visual dos ocupantes - ASE. Dando prosseguimento ao DA, o sDA estabelece uma porcentagem de área do espaço que deve apresentar um valor mínimo de iluminância - 300 lux, por uma fração de tempo - ao menos $50 \%$ das horas ocupadas, representado pela sigla: sDA300/50\%, conforme duas categorias:

- Preferencial (Preferred Daylight Sufficiency), em que a disponibilidade de luz natural deve atender sDA $_{300 / 50 \%}$ por no mínimo $75 \%$ da área do ambiente; e

- Aceitável (Nominally Accepted Daylight Sufficiency), em que ao menos 55\% da área de análise deve estar em conformidade com $\mathrm{sDA}_{300 / 50 \%}$. 
O ASE, por sua vez, é definido como a porcentagem de área do espaço que excede 1.000 lux por mais de 250 horas ocupadas do ano, representado pela sigla ASE1000,250h. Trata-se de um valor relativo que tenta delimitar condições de potencial desconforto visual geradas por incidência direta de sol no plano de trabalho (IESNA, 2012). Sobre o ASE, a IESNA (2012) salienta que as pesquisas que embasaram a definição do método de avaliação de iluminação natural foram baseadas em salas e, portanto, a interpretação do parâmetro ASE em ambientes maiores, como plantas livres de escritórios, ainda é incerta.

O método em questão foi definido com base em pesquisas de campo em 61 ambientes naturalmente iluminados de cidades Norte-americanas; e IESNA (2012) recomenda a utilização conjunta dos parâmetros sDA e ASE em avaliações de edifícios em latitudes e contextos culturais semelhantes aos dos USA.

Já o Useful Daylight Illuminance, ou UDI, foi proposto em 2005 por Nabil e Mardaljevic (2005), e pode ser definido como a ocorrência anual de iluminâncias no plano de trabalho, que pertencem a uma faixa de valores considerada útil. A definição dessa faixa de iluminâncias foi baseada em resultados de estudos de campo que registram as preferências e o comportamento de usuários de edifícios naturalmente iluminados e qualificados por dispositivos operáveis de sombreamento (MARDALJEVIC et al., 2012).

A principal diferença entre os parâmetros DA e UDI é o estabelecimento de um limite superior de valor aceitável de iluminâncias no segundo caso. Sem a definição de um limite superior, o uso do DA está sujeito à ocorrência de níveis elevados de iluminância, vinculados à ocorrência de desconforto visual por ofuscamento e a ganhos térmicos indesejáveis.

Diferente disso, inicialmente, o UDI determinava a faixa entre 100 lux e 2.000 lux, como desempenho adequado. Atualmente, discute-se sobre a expansão ou a redução da faixa de valores aceitos, preferenciais ou toleráveis pelos ocupantes, sempre com base em estudos de campo que foram ou estão sendo realizados em edifícios de escritórios de diferentes localidades.

Os argumentos citados para a expansão do limite superior útil aparecem fortemente vinculados à alta disponibilidade de luz natural do céu dos locais em questão, associada à preferência de alguns usuários por elevados níveis luminosos (chegando a 5.000 lux) para o desempenho de suas tarefas (WYMELENBERG; INANICI, 2014; IESNA, 2012). Por outro lado, o valor máximo de 1.000 lux é um limite considerado "seguro" por evitar qualquer risco de desconforto por ofuscamento além de contribuir para um balanço entre desempenho luminoso e térmico do edifício (SHEN; TZEMPELIKOS, 2012).
Com base em uma gama de trabalhos de campo e referências distintas, sendo citados: Reinhart (2002), Schuler (1995), Baker (2000) e Roche (2002), entre outros, Mardaljevic et al. (2012) propõe uma revisão dos limites de UDI para a faixa entre 100 lux e 3.000 lux, sendo:

- Faixa entre 100 lux e 300 lux: chamada de UDISupplementary, caracterizada pela possível necessidade de uso complementar de iluminação artificial para a realização de atividades como a leitura;

- Faixa entre 300 lux e 3.000 lux: chamada de UDIAutonomous, caracterizada pela baixa probabilidade de uso adicional de iluminação artificial.

Os autores explicam que parte preponderante dos levantamentos foi realizada em grandes edifícios de escritórios (primordialmente nos USA e no Canadá, mas também em cidades Europeias) cujos usuários utilizavam computadores com tecnologia anterior às telas LCD, e acrescentam que a probabilidade de causar ofuscamento com a tecnologia LCD é consideravelmente reduzida em relação às telas de CTR anteriores. Além disso, outro argumento utilizado por Mardaljevic et al. (2012) para o aumento do limite superior de tolerância para iluminância, passando essa de 2.000 lux para 3.000 lux, está atrelado aos aspectos de saúde dos usuários: a manutenção do ritmo circadiano sugere que exposições regulares a altos níveis de iluminância durante $o$ período diurno pode proporcionar efeitos benéficos à saúde a longo prazo.

Ainda assim, Mardaljevic et al. (2012) alerta para a existência de um considerável grau de incerteza na definição da faixa de valores de iluminância preferencial ou tolerável por ocupantes de ambientes de trabalho e, por isso, recomenda que as faixas de UDI sejam tomadas como referências ilustrativas de possibilidades, ao invés de adotadas como metas fixas.

Somado a isso, vale mencionar que o percentual do espaço interno que deve estar com o critério adotado de UDI é outro ponto subjetivo do desempenho luminoso.

Retomando os princípios de uma visão global de projeto sobre o desempenho luminoso dos edifícios, em especial, aqueles de escritórios, Mardaljevic et al. (2009) ressalta que o emprego de métodos de avaliação anual de desempenho luminoso com base no clima permite a obtenção de resultados mais satisfatórios, que façam um balanço entre as exigências de conforto visual, saúde e bem-estar dos ocupantes, e eficiência energética do edifício.

Nesse contexto, menciona-se, ainda, a relevância do uso de dispositivos de sombreamento ou controle solar e sua influência nos desempenhos luminoso e energético do edifício. Tagliabue et al. (2012) afirmam que o 
desconforto visual causado por ofuscamento, via de regra leva os ocupantes a adaptarem as condições ambientais internas notadamente por meio do ajuste de dispositivos de controle solar, o que em muitos casos gera um desempenho de luz natural inferior e um consumo energético do edifício em uso superior àquele estimado em projeto (quando o desempenho ambiental do mesmo é calculado considerando a contribuição da luz natural), já que implica no acionamento de iluminação artificial complementar, além do previsto.

Contemplando os edifícios de escritórios na cidade de São Paulo, tal fato mostra-se ainda mais relevante diante das condições do clima local e das características inerentes à atividade de escritórios. Quanto aos primeiros aspectos, São Paulo (latitude 23030') possui clima subtropical úmido, segundo a classificação da ASHRAE (2009). A disponibilidade de luz natural no céu é alta, chegando-se a 26.000 lux por cerca de $50 \%$ das horas de luz natural do ano (ALUCCI, 2005). Elevada radiação solar incide em todas as orientações durante todo o ano, chegando a um total diário de $4.800 \mathrm{~W} / \mathrm{m}^{2}$ na orientação Norte num dia de inverno; ultrapassando $3.000 \mathrm{~W} / \mathrm{m}^{2}$ nas orientações Leste e Oeste nos meses de outubro a fevereiro; e atingindo $1.000 \mathrm{~W} / \mathrm{m}^{2}$ na Orientação Sul nos meses de verão; ressaltando a necessidade de sombreamento (Ibidem).

Com relação à atividade de escritórios, em particular, sabe-se que além de quantidade de luz, a adequada realização de tarefas e o conforto visual dos ocupantes vai depender de aspectos qualitativos da iluminação, como o controle do ofuscamento, a homogeneidade na distribuição da luz e evitar contrastes excessivos.

Dentre as Normas Técnicas Brasileiras, não há diretrizes específicas para o uso da iluminação natural. A regulamentação mais próxima do tema, a ABNT NBR ISO CIE 8995 (2013), estabelece um nível de iluminância de 500 lux a ser mantido no plano de trabalho de escritórios para atividades de leitura, escrita e uso de computador, considerando apenas a iluminação artificial. Para fins analíticos, isso equivale ao estabelecimento de um limite mínimo de iluminância. Para outras atividades de edifícios de escritórios como cópia, arquivamento e circulação, essa norma define um limite de no mínimo 300 lux, contudo, nesses casos, não se faz distinção entre luz natural e artificial, nem tampouco do seu efeito conjunto. Dessa forma, a referida Norma é normalmente interpretada para o uso exclusivo da luz artificial.

Existem poucos precedentes no campo científico nacional abordando avaliações dinâmicas de desempenho de iluminação natural em espaços de trabalho. A esse respeito, Didoné e Pereira (2010) propõem um método para a avaliação integrada dos desempenhos energético e luminoso de edifícios com base em simulações dinâmicas com os programas Daysim e Energy Plus. Realizando estudo para diversas salas de escritórios na cidade de Florianópolis, o aproveitamento da iluminação natural ao longo do ano é analisado no programa Daysim, conforme um controle dimerizável, estipulado para a iluminação artificial. Os valores horários de ocupação e do acionamento da iluminação artificial são computados e informam a simulação termoenergética no programa Energy Plus. Desse modo, avalia-se a influência da iluminação natural no consumo energético de edifícios.

Prosseguindo em pesquisas brasileiras que abordam o tema, Rocha e Pereira (2011) realizaram simulações dinâmicas integradas de iluminação natural e de desempenho energético para uma sala de escritórios na cidade de Florianópolis com os programas Daysim e EnergyPlus. Nesse trabalho, foco é dado à variação de controles de iluminação artificial e de elementos de proteção solar (venezianas, cortinas, etc), com a representação de comportamentos distintos dos usuários. Os resultados indicam significativa variação de desempenho da iluminação natural em decorrência da aplicação dos diferentes sistemas de proteção solar e do tipo de usuário, passivo (mantém a iluminação artificial ligada e as venezianas parcialmente acionadas o ano todo) ou ativo (considera as condições de iluminação natural para o acionamento dos dispositivos de sombreamento e de iluminação artificial). As variações no controle da iluminação artificial resultaram em diferenças de até $70 \%$ no consumo de energia elétrica do edifício, caso dos sistemas dimerizáveis com as cortinas abertas (i.e., sem sombreamento), em relação aos casos com sistemas de controles relacionados à ocupação no ambiente.

Silva (2011) analisou o impacto de diferentes dispositivos de sombreamento no desempenho da iluminação natural de ambientes de escritórios nas cidades de Brasília, Florianópolis e Maceió. Simulações dinâmicas de iluminação natural foram realizadas com o software Daysim, em termos de DA, para dez modelos de edifícios contemplando três orientações, três porcentagens de área envidraçada na fachada (PAF) e dispositivos horizontais e verticais de sombreamento. Os resultados analisados indicaram que, de modo geral, os menores impactos de redução da autonomia da iluminação natural foram obtidos para a orientação Norte em oposição à Oeste; para os dispositivos de sombreamento verticais alternativamente aos horizontais; e para as cidades com menores latitudes.

Ainda além, Moraes e Pereira (2011) propõem um procedimento simplificado para avaliação da iluminação natural de edificações, com base na relação entre a iluminância externa, sua ocorrência ao longo do ano e a iluminância interna. $\mathrm{O}$ método em questão visa obter os indicadores de desempenho DA e UDI. Os resultados calculados são comparados a simulações anuais de iluminância com o programa Daysim, para três cidades 
Brasileiras: Belém, Brasília e Curitiba. Os autores concluem que o método proposto é confiável e apresenta razoável precisão.

Pereira et al. (2012) avaliaram a relação entre alguns indicadores dinâmicos de desempenho luminoso (FLD, DA e UDI) e a percepção visual de usuários sobre a iluminação natural do espaço. Primeiramente, foi tomado o voto de estudantes de algumas salas de aula da Universidade Federal de Santa Catarina. Na sequência, foram realizadas simulações dinâmicas de iluminação natural dessas salas, para efeitos de comparação dos resultados. O estudo indicou que, de modo geral, a avaliação dos usuários foi mais restritiva do que os resultados obtidos segundo as métricas de iluminação analisadas.

Cartana e Pereira (2017) utilizam ferramentas avançadas de simulação computacional para a modelagem geométrica de elementos de controle solar, informadas por critérios de desempenho luminoso, para um ambiente na cidade de Florianópolis. Os dispositivos de controle solar são modelados parametricamente nos programas Rhinoceros e Grasshopper; o desempenho luminoso é avaliado com a ferramenta Diva-for-Rhino; os cenários que apresentaram no mínimo 85\% de UDI em toda a área do ambiente tem seus dispositivos de sombreamento otimizados pelo programa Galápagos, num processo generativo; e, por fim, a análise de máscaras de sombreamento geradas no plug-in Lady-bug permitem uma melhor visualização e compreensão dos resultados.

Pereira (2017) investigou e testou diversas métricas, critérios e procedimentos para avaliação dinâmica de desempenho luminoso. Com estudo de caso para edifícios de referência a exemplos recentes de escritórios construídos na cidade de São Paulo que receberam certificação ambiental, simulações computacionais anuais foram realizadas com os programas Rhinoceros $3 \mathrm{D}$ e o plug in Diva-for-Rhino. Foi então avaliado o impacto de diversas variáveis arquitetônicas, no desempenho da iluminação natural no edifício. Com base na análise comparativa dos resultados, foi proposto um método de avaliação que integra os desempenhos luminoso, energético e o conforto visual.

Ainda com relação à cidade de São Paulo, exemplos de edifícios de escritórios construídos entre 2005 e 2015 possuem formas predominantemente retangulares ou quadradas, plantas grandes e profundas, core de serviços centralizado, alta densidade de ocupação, amplo uso de equipamentos e sistemas incluindo iluminação artificial e condicionamento artificial por praticamente $100 \%$ do período ocupado (CBCS, 2015). Outras características comuns a grande parte dos projetos arquitetônicos desse período são a presença de forro isolante e piso elevado; e fachadas seladas com uso abundante de vidro, sem janelas operantes e sem elementos externos de proteção solar (MARCONDES, 2010; ANDRADE, 2005; UMAKOSHI, 2014, PEREIRA, 2017). As configurações arquitetônicas desses edifícios, aliadas à vasta e crescente adoção de tecnologias têm resultado comprovadamente em elevados consumos energéticos (CBCS, 2015; MARCONDES, 2010; GONÇALVES; BODE, 2015).

Desse modo, a planta e a fachada desses edifícios de escritórios são parâmetros críticos para o aproveitamento da luz natural. Com áreas de planta extensas e núcleos de circulação centralizados grande parte da área de trabalho fica localizada longe da janela e, com isso, o acesso da iluminação natural nessas áreas fica prejudicado.

\section{Objetivos}

Este trabalho tem como objetivos: analisar o desempenho da luz natural em um típico edifício de escritórios de planta profunda na cidade de São Paulo $\left(2.100 \mathrm{~m}^{2}\right)$ construído entre 2005 e 2015, com e sem dispositivos de sombreamento, por meio de simulações dinâmicas anuais de iluminação natural com base em dados climáticos; e definir a zona passiva para iluminação natural do modelo representativo desses edifícios.

\section{Procedimentos analíticos}

Para o alcance dos objetivos almejados, utilizou-se um método analítico de simulação computacional de iluminação natural, com análise comparativa dos resultados.

As chamadas Avaliações Dinâmicas de Iluminação Natural, ou Avaliações Anuais de Base Climática, foram desenvolvidas para a análise do desempenho luminoso de um edifício de escritórios representativo da produção recente na cidade de São Paulo, para condições de céu e de insolação extraídas da base de dados climáticos horários, específicos de São Paulo, BRA_Sao.Paulo.837800_IWEC.epw (disponível em: https://energyplus.net/weather).

A modelagem geométrica do edifício foi realizada com o software Rhinoceros 5, e o desempenho luminoso dos escritórios foi avaliado com base em simulações anuais de iluminação natural no plug-in Diva-for-Rhino (v.4).

O primeiro critério de avaliação foi o UDI, sendo desejável um mínimo de $75 \%$ do ano, em toda a área de um pavimento tipo de escritório ${ }^{(2)}$. Partiu-se de um UDI de 300 lux a 3.000 lux e testou-se o impacto de ampliações dessa faixa de valores. Esse critério foi analisado e comparado às recomendações da norma ABNT NBR ISO CIE 8995 (2013), ou seja, de um valor mínimo de 500 lux no plano de trabalho. Assim, resultados em termos de DA de 500 lux foram gerados para ilustrar o potencial do ambiente em 
prover um nível mínimo de iluminância ao longo do ano, como recomendado pela Norma Brasileira, porém com o aproveitamento exclusivo da luz natural.

Adicionalmente à avaliação anual, simulações de iluminância foram usadas para ilustrar os detalhes da condição real diária. Isso foi feito para dois dias típicos: um de verão (com céu parcialmente encoberto) e outro de inverno (com céu claro).

\section{Modelo de edifício e cenários de simulação}

Um modelo representativo de edifício foi definido com base em um levantamento de edifícios de escritórios construídos na cidade entre de 2005 e 2015 , contendo 28 casos (após PEREIRA, 2017), a Figura 1 apresenta o modelo criado.

Figura 1 - Visualização do modelo de edifício criado

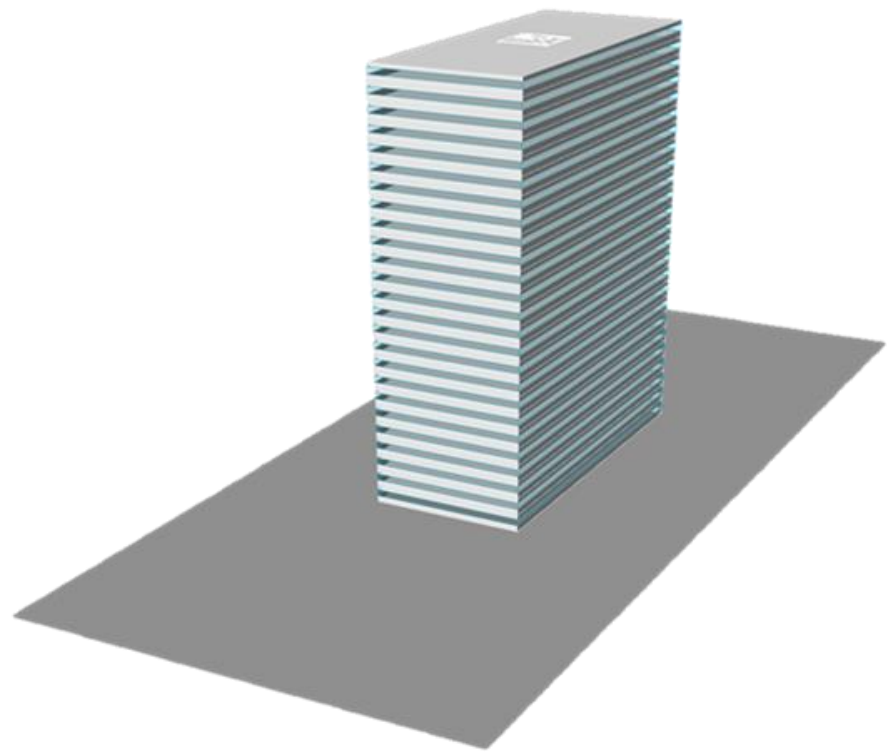

Fonte: Os autores.

Ao todo, $81 \%$ dos edifícios da amostra apresentam forma retangular, e o núcleo de circulação vertical é centralizado em 59\% dos pavimentos tipo. As áreas de laje variam entre $700 \mathrm{~m}^{2}$ e $3.200 \mathrm{~m}^{2}$. Todas as fachadas são seladas com uso abundante de vidro (variando entre $40 \%$ e $100 \%$ da área de fachada), em geral com baixa transmissão luminosa (em torno de $20 \%$ a 30\%), alta absortância (em torno de $60 \%$ ) e em alguns casos com alta refletância (podendo chegar a 50\%), sem sombreamento externo.

De acordo com os objetivos do trabalho, o modelo de estudo possui uma planta profunda, com layout panorâmico, forma retangular e dimensões $70 \mathrm{~m}$ x $30 \mathrm{~m}$ $\left(2.100 \mathrm{~m}^{2}\right)$. Essa compreende plantas de profundidades e áreas menores (dimensões $30 \mathrm{~m}$ x $30 \mathrm{~m}$ e $30 \mathrm{~m}$ x $50 \mathrm{~m}$ ), todas contidas nos limites da amostra. O modelo apresenta núcleo de circulação vertical central com $100 \mathrm{~m}^{2}(10 \mathrm{~m} \mathrm{x}$ $10 \mathrm{~m}$ ), apresentado na Figura 2, e pé direito livre de 2,75 $\mathrm{m}$, conforme a frequência de ocorrência da amostra elencada. A proporção de superfícies envidraçadas ou PAF (percentual de abertura na fachada) é de $70 \%$ (valor médio dentre aqueles da amostra). Como trata-se de um caso base, o modelo em questão apresenta vidro incolor e ausência de sombreamento.

Figura 2 - Planta e corte esquemáticos do edifício. Planta tipo com modulação e demarcação da profundidade máxima de $15 \mathrm{~m}$

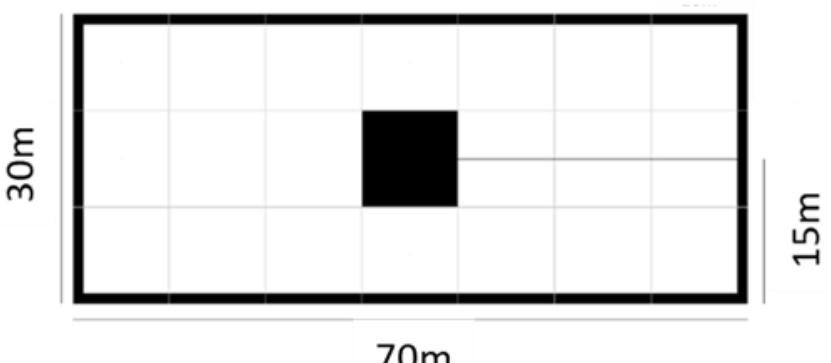

$70 \mathrm{~m}$

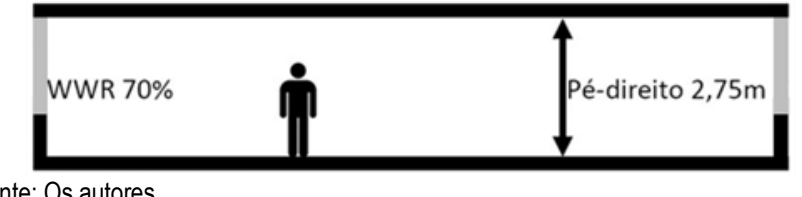

Fonte: Os autores.

Um pavimento típico do edifício de escritórios foi simulado para duas orientações: fachadas principais voltadas a Norte e a Sul, e a Leste e a Oeste. Consideraram-se duas condições distintas: com e sem sombreamento externo do tipo brise-soleil (proteção horizontal externa). Por se tratar de um modelo representativo, não foi considerada obstrução do entorno construído.

O sombreamento foi configurado de modo que: no solstício de verão, a proteção barra totalmente o sol durante todo o dia nas fachadas Norte e Sul, a partir das $8 \mathrm{~h} 00$ na fachada Leste, e até as $16 \mathrm{~h} 00$ na fachada Oeste; e no solstício de inverno o sombreamento acontece por praticamente todo o dia na fachada Norte, a partir das $9 \mathrm{~h} 00$ na fachada Leste, até as $15 \mathrm{~h} 00$ na fachada Oeste e o dia todo na fachada Sul.

\section{Parâmetros de simulação}

Parâmetros construtivos: refletâncias de 70\%, 20\% e 70\% foram atribuídas às paredes internas, piso e teto, respectivamente; e as superfícies transparentes apresentaram transmissão luminosa de 0,88.

Sensores distribuídos em $0,75 \mathrm{~m}$ x $0,75 \mathrm{~m}$ foram posicionados num plano horizontal a $0,75 \mathrm{~m}$ de altura.

As simulações dinâmicas consideraram um período de ocupação do ambiente das 8 h00 às $18 \mathrm{~h} 00$. Na sequência, simulações de iluminância foram realizadas para três horas distintas, dos dias típicos de verão e de inverno: 9h00, $12 \mathrm{~h} 00$ e $15 \mathrm{~h} 00$. 
Para a simulação dinâmica de iluminação natural utilizouse a base de dados climáticos horários de São Paulo BRA_Sao.Paulo.837800_IWEC.epw (disponível em: https://energyplus.net/weather), contendo dados de sete variáveis climáticas: temperatura de bulbo seco $(\mathrm{oC})$, umidade relativa do ar $(\%)$, radiação solar global $\left(\mathrm{W} / \mathrm{m}^{2}\right)$, radiação solar difusa $\left(\mathrm{W} / \mathrm{m}^{2}\right)$, nebulosidade (adimensional), velocidade do ar ( $\mathrm{m} / \mathrm{s})$ e direção do vento $\left(^{\circ}\right)$, para as 8.760 horas de um ano de referência.

A análise dos dados climáticos da cidade indica que a condição de céu varia de parcialmente encoberto a encoberto por cerca de 60\% do ano. Dados dos dois dias típicos, de verão e de inverno, são apresentados a seguir (Figura 3)

Figura 3 - Gráficos com as radiações global, difusa e cobrimento de céu hora a hora para os dias típicos de verão e inverno extraídos do arquivo climático com o ano representativo de 1992.

\section{Dia Típico de Verão}

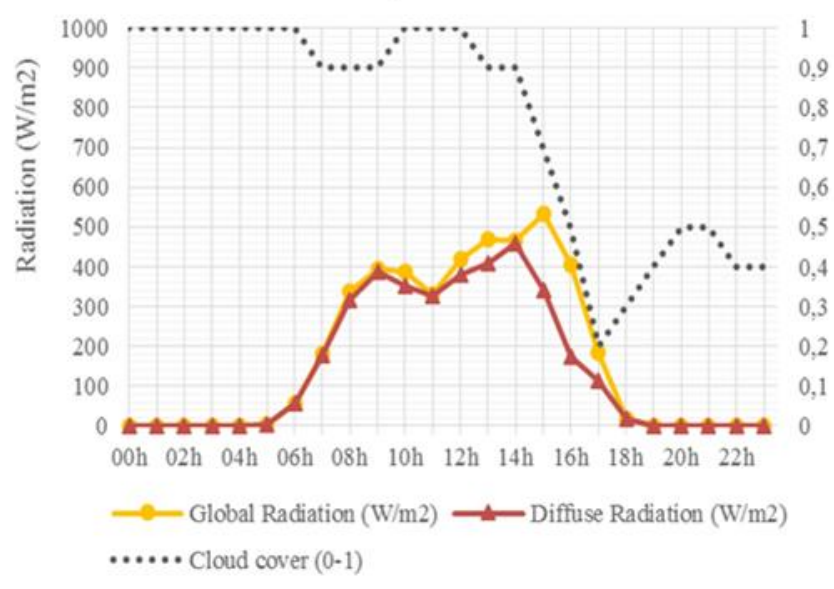

Fonte: Os autores.

\section{Resultados e discussão}

A Figura 4 apresenta os resultados das simulações de UDI300-3.000 e de DA500 para o edifício, com e sem sombreamento externo. Comparando-se as diferentes orientações, notam-se resultados similares, sendo que o edifício predominantemente voltado a Leste/Oeste apresenta resultados sutilmente superiores, podendo-se perceber um aumento das áreas em amarelo.

Observando-se as imagens de UDI nota-se que, como esperado, para fachadas vastamente envidraçadas e sem proteção, a periferia da planta (área de cor azul) ultrapassa 3.000 lux em ambas as orientações. Ou seja, resultados entre 300 lux e 3.000 lux acontecem nessa área por $0 \%$ do ano. Tal fato é comprovado pelos resultados de DA500, que indicam iluminâncias de no mínimo 500 lux nessa porção do ambiente por $100 \%$ das horas ocupadas do ano.

Similarmente, observa-se que a porção mais profunda da planta também apresenta cor azul, indicando resultados inferiores ao limite mínimo estabelecido de 300 lux. Por outro lado, se o limite mínimo aceito passa para 500 lux, verifica-se na simulação de DA500 uma expansão da área central em azul, que não atende ao critério.

Com o uso da proteção solar externa, os níveis excessivos de iluminância na periferia da planta são praticamente

\section{Dia Típico de Inverno}

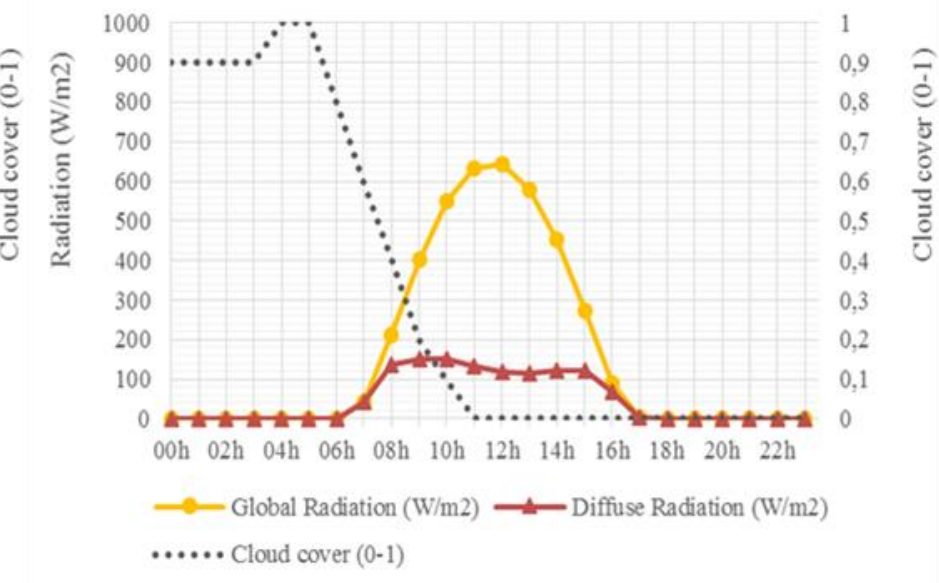

extintos, adequando-se ao valor estipulado como limite máximo de iluminância no caso do UDI, isto é, 3.000 lux. De acordo com os resultados de DA, níveis superiores a 500 lux ainda são encontrados nessa porção do ambiente.

Na parte mais central da planta, nota-se a ampliação da área em azul em todos os casos, aqui representando uma queda nos valores. Isso representa uma maior porção da planta que não chega a apresentar 300 lux ao longo do ano, nas simulações de UDI, e que não alcança 500 lux na simulação de DA, como impacto resultante do brise na planta já profunda.

As imagens da Figura 4 apresentam os resultados de UDI e DA que possibilitam uma avaliação qualitativa comparativa do desempenho luminoso de cada caso. Para quantificar os resultados e a diferença entre os cenários de estudo, a Tabela 1 traz os resultados das simulações em termos da área que atende ao critério estabelecido, UDI ou DA, por no mínimo $75 \%$ das horas do ano. Visando ampliar o entendimento da influência do brise na iluminação natural do ambiente, bem como o impacto da definição do critério de avaliação, são especificados os resultados referentes a quatro faixas de iluminâncias úteis: de 0 a 100 lux, de 100 a 300 lux, de 300 a 3.000 lux e acima de 3.000 lux; e à autonomia da luz natural de 500 lux 
Figura 4- Resultado das simulações anuais em planta de UDI300-3000 e DA500, com e sem brise, para as diferentes orientações; e mascaramentos gerados pelos brises num ponto de simulação próximo a fachada.

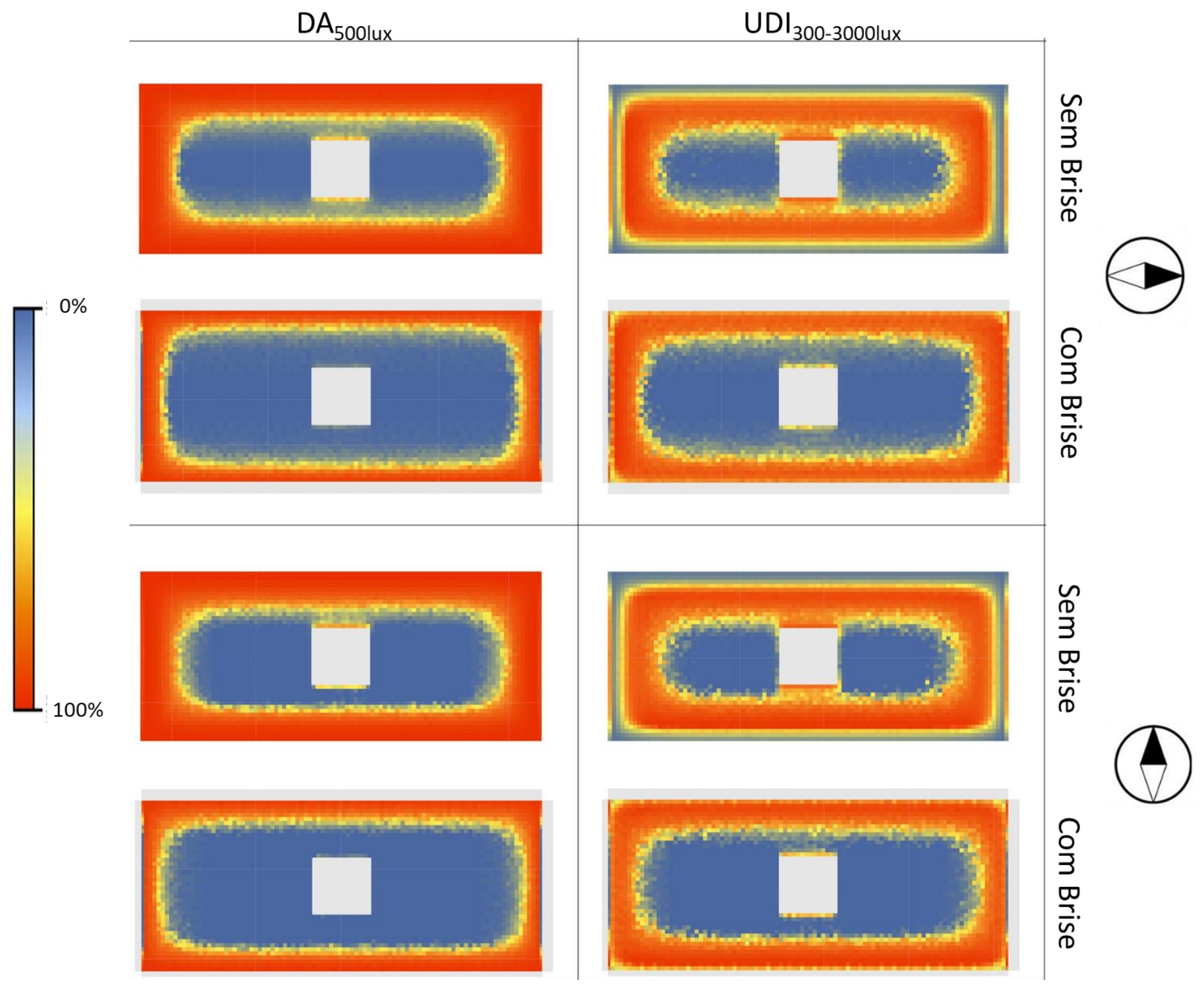

\section{Mascaramento dos Brises}

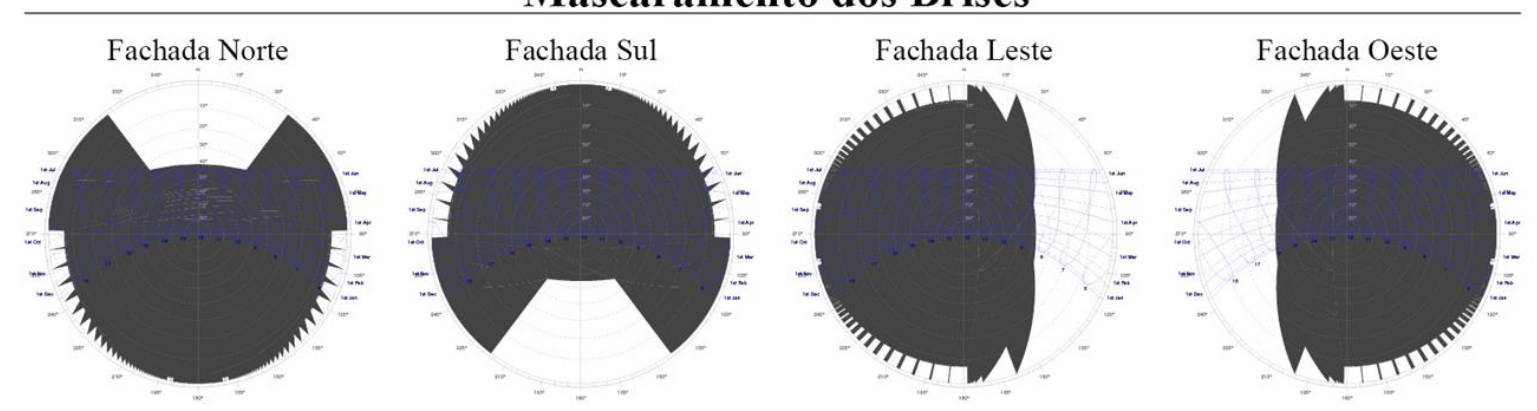

Fonte: Os autores. 
Tabela 1 -Área da planta que atende ao critério de UDI ou DA por no mínimo $75 \%$ do ano

\begin{tabular}{|c|c|c|c|}
\hline Características & \multicolumn{2}{|c|}{ UDI } & $\mathrm{DA}_{500}$ \\
\hline \multirow{4}{*}{ Sem brise } & $0-100 \operatorname{lux}$ & $1,8 \%$ da área & \multirow{4}{*}{$51,0 \%$ da área } \\
\hline & $100-300 \operatorname{lux}$ & $10,7 \%$ da área & \\
\hline & $300-3.000 \operatorname{lux}$ & $39,5 \%$ da área & \\
\hline & $>3.000 \operatorname{lux}$ & $11,3 \%$ da área & \\
\hline \multirow{4}{*}{ Com brise } & $0-100 \operatorname{lux}$ & $11,9 \%$ da área & \multirow{4}{*}{$27,6 \%$ da área } \\
\hline & $100-300 \operatorname{lux}$ & $17,1 \%$ da área & \\
\hline & $300-3.000 \operatorname{lux}$ & $38,3 \%$ da área & \\
\hline & $>3.000 \operatorname{lux}$ & $0,0 \%$ da área & \\
\hline \multirow{4}{*}{ Sem brise } & $0-100 \operatorname{lux}$ & $0,6 \%$ da área & \multirow{4}{*}{$50,2 \%$ da área } \\
\hline & $100-300 \operatorname{lux}$ & $6,6 \%$ da área & \\
\hline & $300-3.000 \operatorname{lux}$ & $32,7 \%$ da área & \\
\hline & $>3.000 \operatorname{lux}$ & $12,1 \%$ da área & \\
\hline \multirow{4}{*}{ Com brise } & $0-100 \operatorname{lux}$ & $14,6 \%$ da área & \multirow{4}{*}{$24,8 \%$ da área } \\
\hline & $100-300 \operatorname{lux}$ & $9,0 \%$ da área & \\
\hline & $300-3.000$ lux & $35,3 \%$ da área & \\
\hline & $>3.000 \operatorname{lux}$ & 0,0\% da área & \\
\hline
\end{tabular}

Fonte: Os autores

A análise dos resultados indica que, se considerada adequada a faixa de valores entre 300 lux e 3.000 lux, pode-se dizer que os resultados com e sem a proteção solar externa são equivalentes, ocorrendo uma redução de $1,2 \%$ da área para a orientação Norte/Sul e um aumento de 2,3\% da área para a orientação Leste/Oeste. Entretanto, se a faixa de valores aceita é expandida e engloba de 100 lux a 3.000 lux, nota-se um aumento de cerca de 5\% da área em ambos os casos com o uso do brise, chegando a 55,4\% na orientação Norte/Sul

Observa que, com o sombreamento, um acréscimo de $10 \%$ e de $14 \%$ de área acontece nas orientações Norte/Sul e Leste/Oeste, respectivamente, para resultados inferiores a 100 lux. Tal fato indica que, nessas áreas, existirá a necessidade de uso de iluminação artificial complementar. Porém, em ambas as orientações os valores superiores a 3.000lux, que aconteciam em aproximadamente $12 \%$ da área do escritório, são extintos com a proteção solar ${ }^{(3)}$; esse fato é altamente relevante por ser indicativo da redução do risco de ofuscamento e, possivelmente, também do desconforto térmico por sobre aquecimento nesses ambientes.

Já em termos de DA, nota-se resultados equivalentes entre as orientações, com variações inferiores a $3 \%$. Com esse critério, o desempenho anual de iluminação natural dos escritórios mostra-se adequado por ao menos $75 \%$ do ano em cerca de $50 \%$ da área da planta dos dois casos analisados. Com o uso do brise, tal desempenho cai praticamente pela metade, já que os resultados acima de 3.000 lux considerados adequados por esse critério não acontecem mais, e que ocorre uma ampliação de valores inferiores a 500 lux. Vale ressaltar que, apesar da queda dos valores de DA com o sombreamento, tal fato não é necessariamente indicativo de um desempenho luminoso prejudicado, uma vez que, como já mencionado anteriormente, o mínimo necessário de 500 lux para as tarefas de escritório é questionado por referências internacionais de desempenho (REINHART; MARDALJEVIC; ROGERS, 2006; WYMELENBERG; INANICI, 2014).

De modo a complementar a avaliação, o Gráfico 1 e o Gráfico 2 trazem dados numéricos obtidos nas simulações de UDI para duas faixas de valores: entre 100 lux e 300 lux, e entre 300lux e 3.000 lux. Os gráficos correspondem a cortes longitudinais na planta dos edifícios, com valores de UDI indicados a cada 3,00 m. Desse modo, é possível analisar o desempenho da iluminação natural resultante dessa configuração de edifício, para cada orientação, de acordo com a profundidade da planta ou distância da fachada. Note-se que a parte central do gráfico ilustra o efeito de reflexão das paredes do núcleo vertical de circulação, aumentando os níveis de iluminância. Nesse caso, utilizou-se uma refletância de $70 \%$ para essas paredes internas. Enfatiza-se que no modelo representativo em estudo a planta de escritórios recebe luz natural das quatro fachadas, com distancias de até $15 \mathrm{~m}$ na transversal e distancias de até $30 \mathrm{~m}$ na maior dimensão da planta - aquela ilustrada na Figura 2.

Vale destacar que os gráficos em análise trazem resultados de simulações anuais. Diferentemente de uma avaliação de iluminância de um dia, a flutuação observada nos resultados em estudo deve-se à condição dinâmica da luz natural, sujeita a variações a cada instante, especialmente em diferentes horas do dia e diferentes épocas do ano.

Nos dois casos analisados, isto é, orientações predominantes Norte/Sul (seção Oeste-Leste) e Leste/Oeste (seção Norte-Sul), observa-se o efeito do brise deslocando a curva de UDI em direção à periferia da área de trabalho, permitindo o seu melhor aproveitamento. Desse modo, os gráficos reforçam os resultados anteriores (Figura 4 e Tabela 1), que ilustram a redução ou exclusão de resultados acima de 3.000 lux na parte periférica da planta com o sombreamento.

Ainda com relação ao uso da proteção solar externa, notase uma queda brusca da curva de 100-300 lux no interior da planta. Por exemplo, observa-se que valores entre 100 lux e 300 lux acontecem em menos de $50 \%$ das horas ocupadas no ano (UDI 50\%) a partir de: $14 \mathrm{~m}$ da fachada Oeste, 12,5 $\mathrm{m}$ da fachada Leste, $10 \mathrm{~m}$ da fachada Norte e $11 \mathrm{~m}$ da fachada Sul. Isso significa que a frequência de ocorrência de iluminâncias inferiores a 100 lux é aumentada nessas áreas mais profundas da planta. 
Gráfico 1 - Iluminâncias úteis ao longo da profundidade da planta, com e sem brise. Seção Norte - Sul

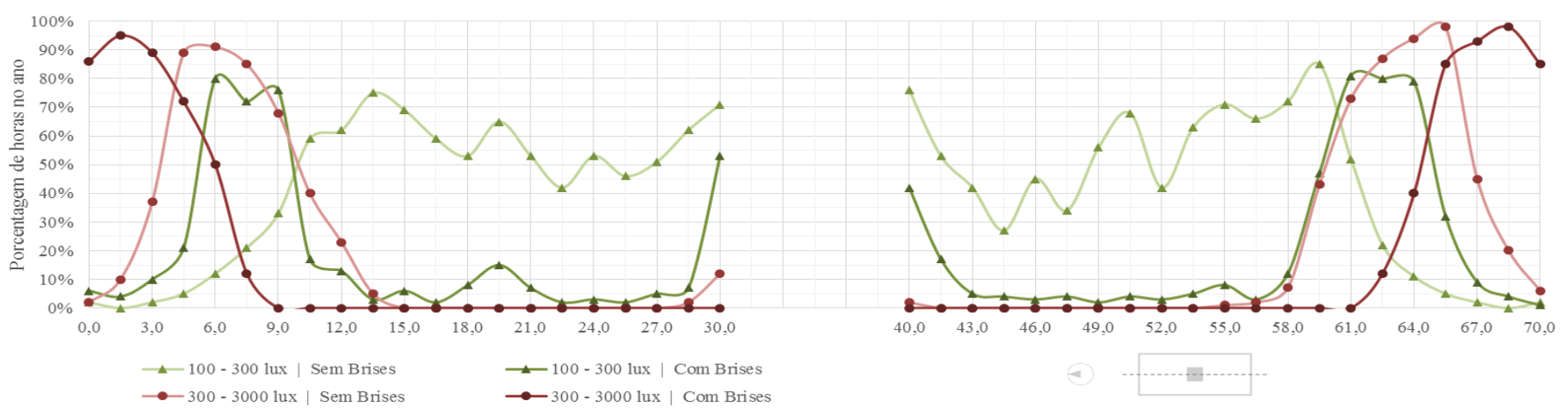

Fonte: Os autores

Gráfico 2 - lluminâncias úteis ao longo da profundidade da planta, com e sem brise. Seção Oeste - Leste

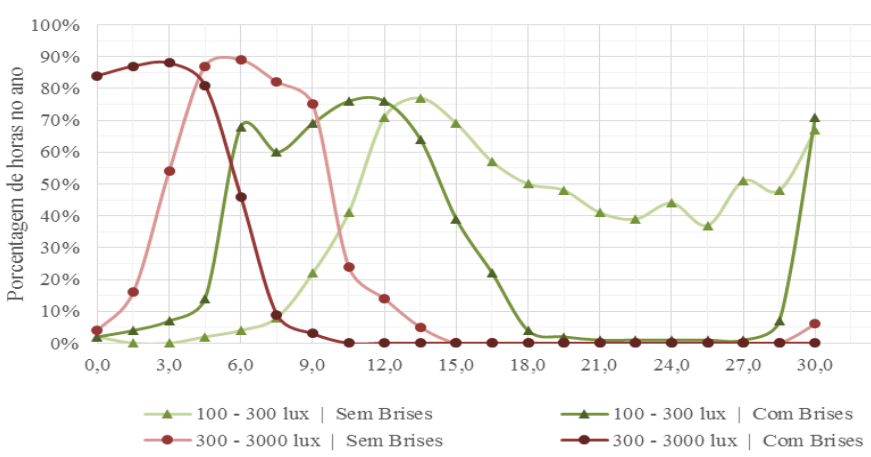

Fonte: Os autores

Considerando o aproveitamento da periferia da planta permitido pelo uso de proteção solar externa para os casos e condições específicos avaliados neste trabalho, de acordo com os gráficos 1 e 2 pode-se dizer que uma faixa ou zona passiva de iluminação natural, para atender ao critério de $75 \%$ de $\mathrm{UDI}_{300-3.000}$, seria possível: até $3,5 \mathrm{~m}$ da fachada Leste, até 4,5 $\mathrm{m}$ da fachada Norte e até $5 \mathrm{~m}$ das fachadas Oeste e Sul. Entretanto, incluindo-se a faixa de iluminâncias entre 100 lux e 300 lux, isto é, ampliando-se o critério para $\mathrm{UDI}_{100-3.000}$, a zona passiva poderia chegar a $9 \mathrm{~m}$ das fachadas Norte e Sul, a $10 \mathrm{~m}$ da fachada Leste e até12 $\mathrm{m}$ da fachada OesteAs Figuras 5 a 8 trazem os níveis de iluminância obtidos nas simulações dos dois dias típicos selecionados para São Paulo, e os gráficos 3 a 6 ilustram esses resultados ao longo de uma seção no eixo longitudinal da planta do escritório, em três horários 9h00, $12 \mathrm{~h} 00$ e $15 \mathrm{~h} 00$.

Evidencia-se, novamente, que o impacto do brise é mais significativo na proximidade das fachadas, gerando quedas expressivas nos níveis de iluminância, sobretudo nas horas em que a radiação solar direta incide nessas superfícies. Como exemplo, considerando-se uma distância de 1,5 m da fachada, que já poderia abrigar um posto de trabalho, o resultado de 16.416 lux encontrado a Oeste às $15 \mathrm{~h} 00$ do dia típico de verão tem uma queda de $82 \%$ em seu valor com o uso do brise, passando para 2.880 lux. De modo análogo, às $12 \mathrm{~h} 00$ do dia típico de inverno os níveis de iluminância obtidos próximo a $1,5 \mathrm{~m}$ da fachada Norte caem $95 \%$ com o sombreamento externo, passando de 53.616 lux para 2.668 lux e, consequentemente, eliminando o ofuscamento.

Em direção ao centro da planta o efeito do brise diminui, onde o acesso a luz natural já é normalmente dificultado a grandes distâncias de uma fachada não sombreada. Nesses casos, observa-se que a curva do nível de iluminância fica mais estável a uma distância de aproximadamente $15 \mathrm{~m}$ das fachadas mais afastadas do núcleo de circulação vertical. De modo geral, verifica-se que nessas partes do ambiente ocorrem reduções de cerca de 50\% no nível de iluminância com a inserção do brise, passando de aproximadamente 200 lux para aproximadamente 100 lux em todos os casos e horários considerados.

Se considerado um limite superior aceitável de iluminância, a análise dos resultados por orientação sem o sombreamento externo ilustra que, no dia típico de verão, iluminâncias ultrapassam 3.000 lux: até $3,0 \mathrm{~m}$ das fachadas Norte e Sul, em todos os horários de análise; na fachada Oeste, às 9:00 horas a 1,5 m, às 12:00 horas até $3,0 \mathrm{~m}$ e às $15: 00$ horas até $4,5 \mathrm{~m}$ da fachada; e na orientação Leste às $9 \mathrm{~h} 00$ até $4,5 \mathrm{~m}$ e nos demais horários até $3,0 \mathrm{~m}$ da fachada. Já no dia de inverno, valores superiores a 3.000 lux são verificados até $4,5 \mathrm{~m}$ da fachada 
Figura 1- Simulações de iluminância em planta de eixo Norte Sul para o dia típico de verão, com delimitação, em linha tracejada, dos pontos utilizados para a elaboração do gráfico 3

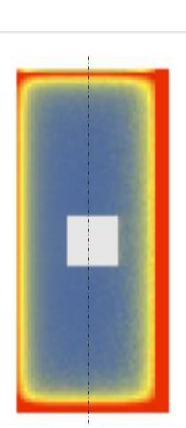

$9 \mathrm{~h}$
Sem Brise

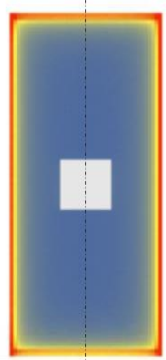

$12 \mathrm{~h}$

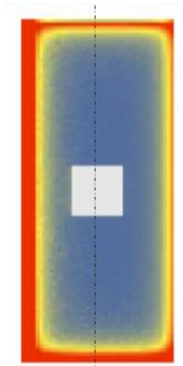

$15 \mathrm{~h}$

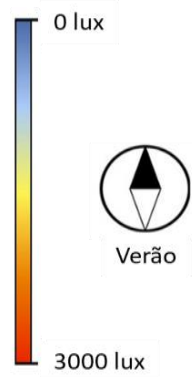

3000 lux

Fonte: Os autores.

Gráfico 3 - Ìndices de iluminância para dia típico de verão às $9 \mathrm{~h} 00,12 \mathrm{~h} 00$ e 15h00, com e sem brise, para a seção Norte-Sul
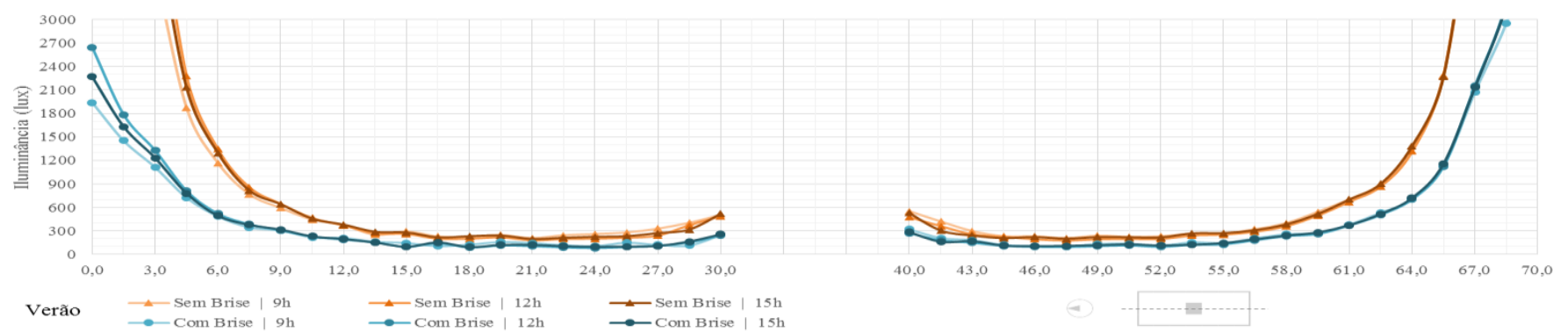

Fonte: Os autores

Figura 2 - Simulações de iluminância em planta de eixo Norte Sul para o dia típico de inverno, com delimitação, em linha tracejada, dos pontos utilizados para a elaboração do gráfico 4

Sem Brise

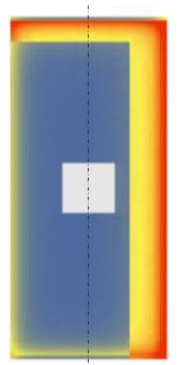

$9 \mathrm{~h}$

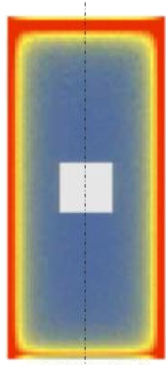

$12 \mathrm{~h}$

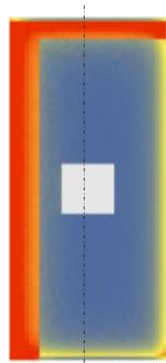

$15 \mathrm{~h}$

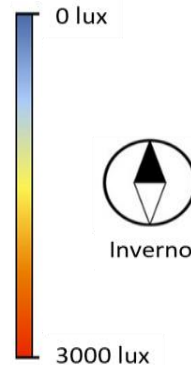

3000 lux

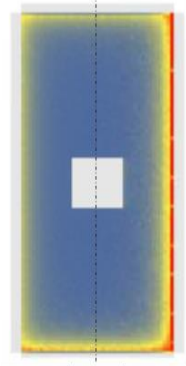

$9 \mathrm{~h}$
Com brise

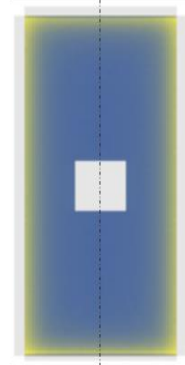

$12 \mathrm{~h}$

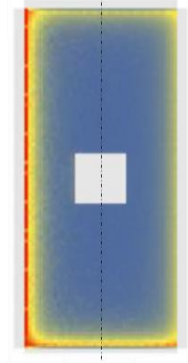

$15 \mathrm{~h}$

Fonte: Os autores

Gráfico 4 - İndices de iluminância para dia típico de inverno às 9h00, $12 \mathrm{~h} 00$ e 15h00, com e sem brise, para a seção Norte-Sul
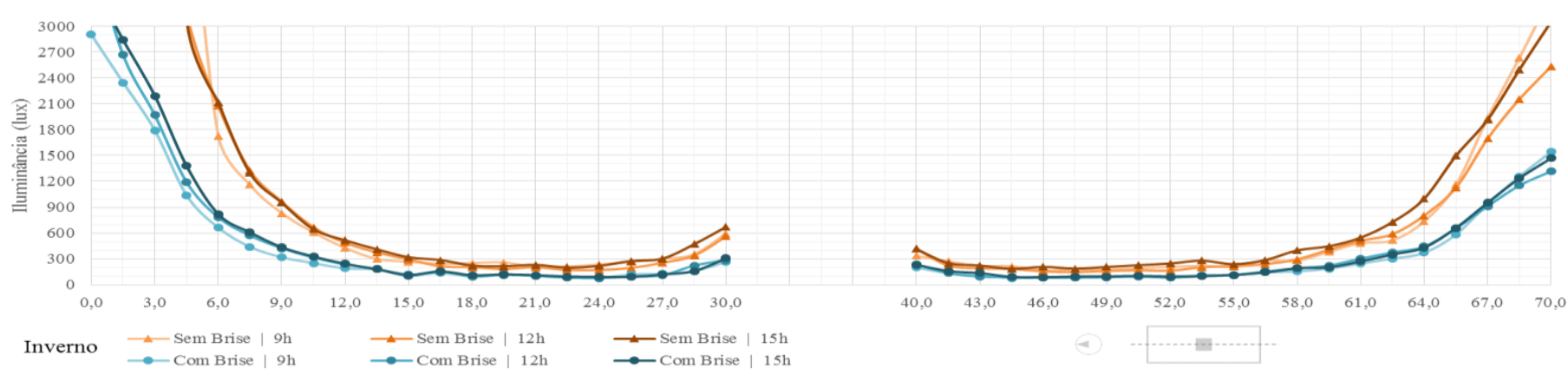

Fonte: Os autores. 
Figura 3 - Simulações de iluminância em planta de eixo Leste Oeste para o dia típico de verão, com delimitação, em linha tracejada, dos pontos utilizados para a elaboração do gráfico 5

$$
\text { Sem Brise }
$$

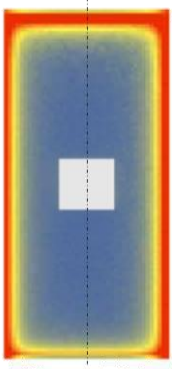

$9 \mathrm{~h}$

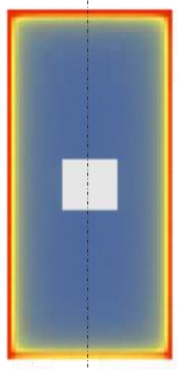

$12 \mathrm{~h}$

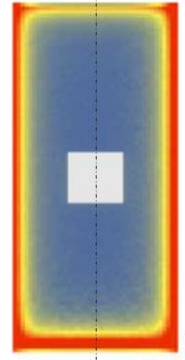

$15 \mathrm{~h}$

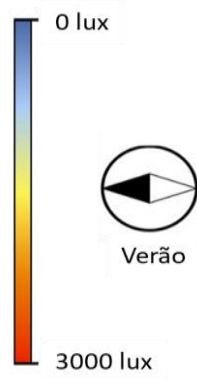

$3000 \operatorname{lux}$

Fonte: Os autores.

Gráfico 5 - İndices de iluminância para dia típico de verão às $9 \mathrm{~h}, 12 \mathrm{~h}$ e $15 \mathrm{~h}$, com e sem brise, para a seção Leste-Oeste
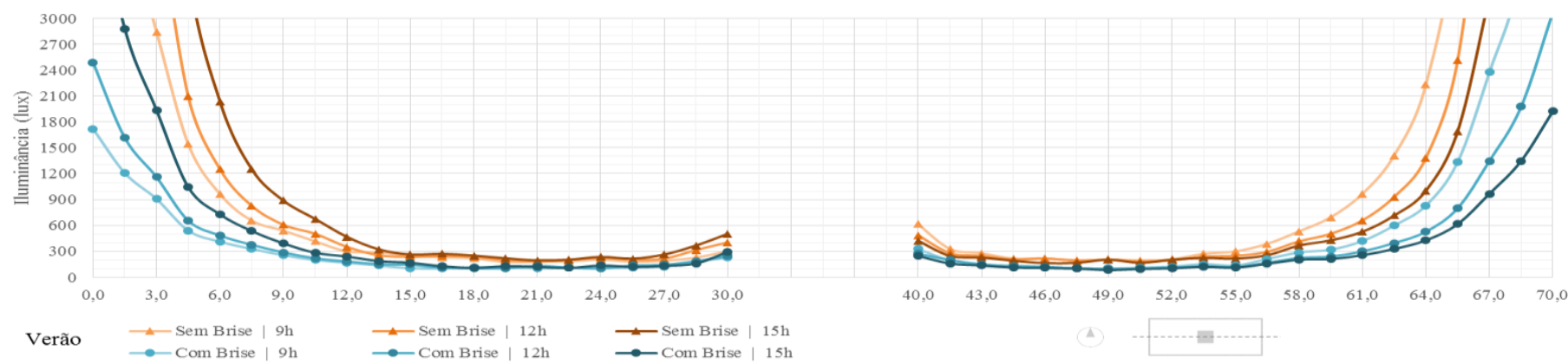

Fonte: Os autores.

Figura 4 - Simulações de iluminância em planta de eixo Leste Oeste para o dia típico de inverno, com delimitação, em linha tracejada, dos pontos utilizados para a elaboração do gráfico 6

Sem Brise

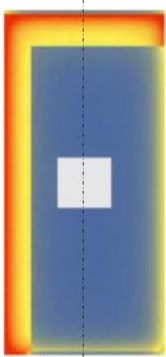

$9 \mathrm{~h}$

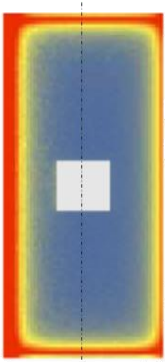

$12 \mathrm{~h}$

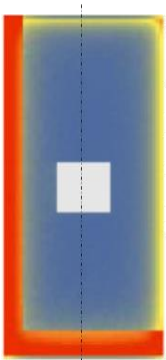

$15 \mathrm{~h}$

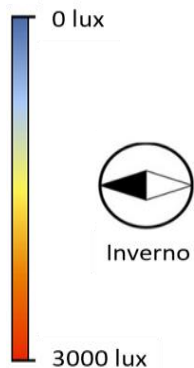

3000 lux

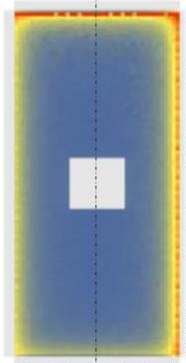

$9 \mathrm{~h}$
Com brise

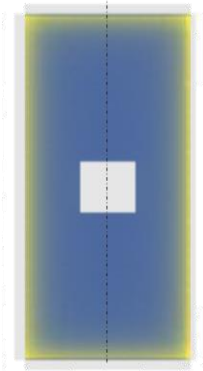

$12 \mathrm{~h}$

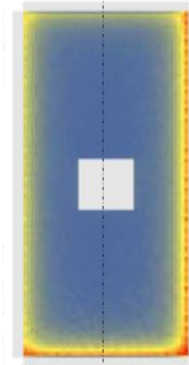

$15 \mathrm{~h}$

Fonte: Os autores.

Gráfico 6 - İndices de iluminância para dia típico de inverno às 9 h00, 12 h00 e 15h00, com e sem brise, para a seção Leste-Oeste.
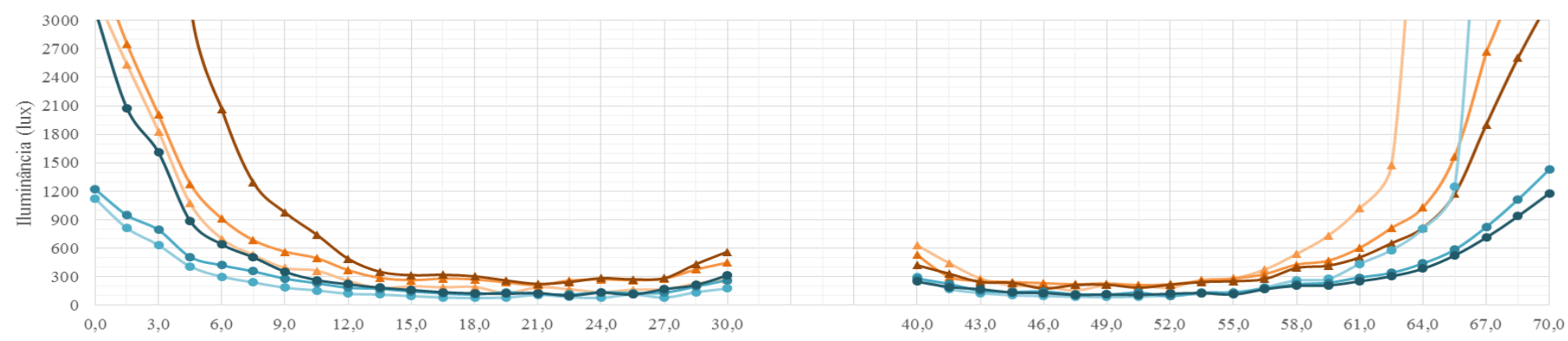

Inverno $\longrightarrow$ Sem Brise $\mid 9 \mathrm{~h} \quad \longrightarrow$ Sem Brise $\mid 12 \mathrm{~h} \quad \longrightarrow$ sem Brise $\mid 15 \mathrm{~h}$

Fonte: Os autores. 
Norte nos horários verificados; até $4,5 \mathrm{~m}$ da fachada Oeste às $15 \mathrm{~h} 00$; e na orientação Leste, até $6,0 \mathrm{~m}$ às $9 \mathrm{~h} 00$ e a 1,5 $\mathrm{m}$ às $12 \mathrm{~h} 00$. Em todos esses casos, o uso do brise permitiu que os valores de iluminância ficassem inferiores a 3.000 lux.

Por outro lado, considerando-se um limite mínimo do nível de iluminância no edifício, com o uso do sombreamento externo, valores superiores ou iguais a 300 lux foram encontrados: no dia de verão, até $9,0 \mathrm{~m}$ nas orientações Norte e Sul; na fachada Oeste, até 7,5 m às $9 \mathrm{~h} 00$ e às $12 \mathrm{~h} 00$ e até $9,0 \mathrm{~m}$ às $15 \mathrm{~h} 00$; e na fachada Leste, até $10,5 \mathrm{~m}$ às $9 \mathrm{~h} 00$, até $9,0 \mathrm{~m}$ às $12 \mathrm{~h} 00 \mathrm{e}$ até $7,5 \mathrm{~m}$ às 15h00. No dia de inverno, um mínimo de 300 lux foi obtido na orientação Norte até $9,0 \mathrm{~m}$ às 9 h00 e até $10,5 \mathrm{~m}$ nos demais horários; até $9,0 \mathrm{~m}$ às $12 \mathrm{~h} 00$ e até $7,5 \mathrm{~m}$ às 9 h00 e às $15 \mathrm{~h} 00$ na fachada Sul; até $7,5 \mathrm{~m}$ às 9 h00 e às $12 \mathrm{~h} 00$ na fachada Oeste e até $9,0 \mathrm{~m}$ às $15 \mathrm{~h} 00$; e até $9,0 \mathrm{~m}$ às $9 \mathrm{~h} 00$ e até 7,5 m nos demais horários na fachada Leste.

Por fim, de acordo com os resultados obtidos, a definição de uma faixa passiva para iluminação natural do edifício de escritórios em São Paulo vai depender do critério escolhido para avaliar o desempenho luminoso. A Tabela 2 ilustra potenciais zonas passivas para os casos e condições específicos deste estudo, considerando-se dois critérios de avaliação distintos: UDI300-3000 e UDI1003000. Adicionalmente, a área da planta que atende a cada um dos critérios é apresentada para as orientações de edifício avaliadas.

$\mathrm{Na}$ orientação Leste, por exemplo, verifica-se uma zona passiva de até 3,5 m conforme o critério UDI300-3000; alternativamente, se o critério for ampliado para UDI1003000 , a zona passiva passa a ser praticamente três vezes maior, chegando a $10,0 \mathrm{~m}$. Para o edifício com faces principais voltadas a Leste e a Oeste, essa alteração de critério corresponderia a um aumento de $9 \%$ na área da planta em conformidade, passando de 35,3\% da área da planta no primeiro caso, para $44,3 \%$ da área contemplada no segundo caso (Tabela 2).

\begin{tabular}{c|c|c|c|c}
\hline \multirow{2}{*}{ Tabela 2 - Critérios de avaliação e zona passiva para o edifício em análise } \\
\hline & \multicolumn{4}{|c}{$\begin{array}{c}\text { Zona passiva (Distância a partir da } \\
\text { fachada) }\end{array}$} \\
\cline { 2 - 5 } & $\begin{array}{c}\text { Fachada } \\
\text { Norte }\end{array}$ & $\begin{array}{c}\text { Fachada } \\
\text { Sul }\end{array}$ & $\begin{array}{c}\text { Fachada } \\
\text { Leste }\end{array}$ & $\begin{array}{c}\text { Fachada } \\
\text { Oeste }\end{array}$ \\
\hline UDI $_{300-3000}$ & $4,5 \mathrm{~m}$ & $5,0 \mathrm{~m}$ & $3,5 \mathrm{~m}$ & $5,0 \mathrm{~m}$ \\
\hline UDl $_{100-3000}$ & $9,0 \mathrm{~m}$ & $9,0 \mathrm{~m}$ & $10,0 \mathrm{~m}$ & $12,0 \mathrm{~m}$ \\
\hline
\end{tabular}

\begin{tabular}{c|c|c}
\hline \multirow{2}{*}{ Critério } & \multicolumn{2}{|c}{ Área da planta correspondente } \\
\cline { 2 - 3 } & & \\
\hline UDI $_{300-3000}$ & $38,3 \%$ & $35,3 \%$ \\
\hline UDl $_{100-3000}$ & $55,4 \%$ & $44,3 \%$ \\
\hline
\end{tabular}

\section{Conclusão}

O desempenho da iluminação natural em um típico edifício de escritórios do período de 2005 a 2015, na cidade de São Paulo, foi analisado considerando fachadas envidraçadas com e sem dispositivos externos de proteção solar, por meio de simulações dinâmicas de luz natural baseadas em dados climáticos anuais, em inglês: ClimateBased Dinamic Modelling (CBDM).

Resultados em termos de UDI foram comparados ao estabelecimento de um valor mínimo de iluminância de 500 lux para o escritório. Conclui-se que a medida UDI mostra-se mais adequada por apresentar um limite máximo e, desse modo, contribui para a prevenção da ocorrência de desconforto visual por ofuscamento. Tendo em vista o contexto climático local, pode-se dizer que o estabelecimento de um limite máximo de iluminâncias também pode auxiliar na prevenção de desconforto térmico por sobreaquecimento.

Limites mínimos de UDI de 100 lux e 300 lux foram simulados e comparados, possibilitando quantificar o impacto do estabelecimento desse critério no desempenho do edifício.

Diante da alta disponibilidade de luz natural no céu de São Paulo, do potencial de trabalhar a arquitetura - mais especificamente o projeto da fachada e de elementos de controle solar - para maximizar o aproveitamento da luz natural no interior dos ambientes de trabalho, e do atual caráter de flexibilidade crescente nos edifícios de escritórios, com áreas de transição e postos de trabalho coletivos e rotativos, o critério ampliado de 100 lux a 3.000 lux é cabível. Frente a essa proposta arquitetônica e ambiental de amplo aproveitamento da iluminação natural, vale lembrar que o intervalo de 100 lux a 300 lux de luz natural cria condições úteis para uma série de atividades em um edifício de escritórios, sem a necessidade de complementação da luz artificial.

Este trabalho visou contribuir para a definição de uma faixa passiva para iluminação natural de edifícios de escritórios em São Paulo. Essa definição demanda um aprofundamento dos estudos, abordando cada orientação e configuração específica de edifício. No caso do modelo referencial ora analisado, de acordo com o critério de desempenho estipulado - sendo UDI300-3000 ou UDI100-3000, a zona passiva para iluminação natural estaria distanciada da fachada conforme indicado na Tabela 2. Para a orientação Norte, por exemplo, a zona passiva seria de até 4,5 m com UDI300-3000 e até 9,0 m com UDI100-3000.

Dentre todos os casos aqui analisados, $75 \%$ de UDI foi obtido em no máximo $55,4 \%$ da área do escritório no cenário Norte/Sul com brise considerando a faixa expandida de UDI100-3000. Ou seja, mesmo nos 
melhores cenários, os resultados das simulações evidenciaram a dificuldade de obtenção de $75 \%$ de UDI na área total do escritório. Como já mencionado, nas porções mais distantes das fachadas a influência do brise é menor e, portanto, tal fato é resultado de uma planta profunda (aqui com até $15 \mathrm{~m}$ de distância da janela), que dificulta o acesso à luz natural em suas áreas centrais.

Com relação aos resultados considerados insuficientes (i.e., inferiores a 100 lux), nota-se que o uso do brise provocou um aumento de $10 \%$ da área prejudicada na orientação Norte/Sul e $14 \%$ da mesma na orientação Leste/Oeste. Por outro lado, ao cortar níveis de iluminância excessivos na área ocupada junto à fachada, as proteções externas permitem um melhor aproveitamento da periferia da planta, sendo seu impacto reduzido em direção ao centro da planta. Normalmente, sem a presença das proteções solares externas e sob a ocorrência de ofuscamento, usuários de ambientes de trabalho tendem a acionar proteções solares internas que reduzem o aproveitamento da luz natural.

Por tudo isso, os resultados das simulações com proteção solar externa apontam para a necessidade de se trabalhar o projeto dos brises, a fim de aprimorar seu desenho para o aproveitamento da luz natural. Estratégias como o sombreamento dinâmico, em inglês: dynamic shades (KONSTANTZOS; TZEMPELIKOS; CHAN, 2015) e a parametrização do projeto do brise, isto é, o dimensionamento conforme a exposição à radiação solar (CARTANA; PEREIRA, 2017) podem ser exploradas.

Etapas futuras desta pesquisa pretendem: incluir o entorno construído na caracterização dos edifícios; testar diferentes tipos de vidros nas fachadas; e analisar a questão do ofuscamento no ambiente de trabalho; aspectos considerados limitações do presente estudo.

\section{Agradecimentos}

Os autores agradecem à Coordenação de Aperfeiçoamento de Pessoal de Nível Superior, CAPES, pela concessão de uma bolsa de Pós-Doutorado, e à Fundação de Amparo à Pesquisa do Estado de São Paulo, FAPESP, pela bolsa de Iniciação Científica.

\section{Notas}

(1) O Daylight Factor é a razão entre a iluminância em um ponto no interior de um edifício e a iluminância no plano horizontal externo desobstruído, sob céu encoberto do tipo CIE (MOON; SPENCER, 1942).

(2) Este trabalho pretendeu adotar um critério mais rigoroso do que referências internacionais, como o sDA, tendo em vista o potencial do céu de São Paulo.

(3) A avaliação em questão considerou os resultados ocorridos em no mínimo $75 \%$ do tempo. Desse modo, é possível que ocorra algum resultado acima de 3.000 lux em poucas horas do ano.

\section{Referências}

ALUCCI, M. P. Software de Conforto. Climaticus_2011(beta).xlsm. Disponível em:

http://www.fau.usp.br/pesquisa/laboratorios/labaut/conforto/index.html. Acesso em: 16.10.2017.

ANDERSEN, M. Unweaving the human response in daylight design. Building and Environment. v. 91, p.101-117, set. 2015. doi:https://doi.org/10.1016/j.buildenv.2015.03.014

ANDRADE, C. M. Avaliação de desempenho em edifícios de escritório: o ambiente de trabalho como meio para o bem-estar produtivo. 2005. Tese (Doutorado) - Faculdade de Arquitetura de Urbanismo, Universidade de São Paulo, São Paulo, 2005.

ASHRAE - AMERICAN SOCIETY OF HEATING, REFRIGERATING AND AIR CONDITIONING. ASHRAE Handbook Fundamentals. Atlanta: ASHRAE, 2009

ABNT - ASSOCIAÇÃO BRASILEIRA DE NORMAS TÉCNICAS. NBR ISO/CIE 8995: Iluminação de ambientes de trabalho. Parte 1 - Interior. Rio de Janeiro, 2013.

BAKER, N. We are all outdoor animals. In: ANNUAL CONFERENCE OF PASSIVE AND LOW ENERGY ARCHITECTURE, Cambridge, 2000. Proceedings of PLEA 2000... London: James \& James (Science Publishers) Ltd, 2000. p. 553-554.

CARTANA, Rafael Prado; PEREIRA, Fernando Oscar Ruttkay. Elementos de controle solar desenvolvidos com modelagem paramétrica e algoritmos evolutivos. PARC Pesquisa em Arquitetura e Construção, Campinas, SP, v. 7, n. 3, p. 133-144, out. 2016. ISSN 1980-6809. doi:doi:https://doi.org/10.20396/parc.v7i3.8647516. 


\section{CBCS - CONSELHO BRASILEIRO DE CONSTRUÇÃO SUSTENTÁVEL. Benchmarking de escritórios corporativos e} recomendações para certificação DEO no Brasil. Relatório Final. São Paulo, 2015.

DIDONÉ, Evelise Leite; PEREIRA, Fernando Oscar Ruttkay. Simulação computacional integrada para a consideração da luz natural na avaliação do desempenho energético de edificações. Ambient. constr. (Online), Porto Alegre, v. 10, n. 4, p. 139-154, Dec. 2010 . doi:http://dx.doi.org/10.1590/S1678-86212010000400010.

GONÇALVES, J.C.S., BODE, K. (Org.) Edifício Ambiental. São Paulo: Oficina de textos, 2015. 592p.

GONÇALVES, J.C.S.; FERNANDEZ, J.M. The Environmental Design of Working Spaces in Equatorial Highlands Zones: the case of Bogotá. Buildings. Buildings, v. 5, n. 4, p.1105-1130, out. 2015. doi:https://doi.org/10.3390/buildings5041105

IESNA - ILLUMINATING ENGINEERING SOCIETY OF NORTH AMERICA. IES LM-83-12. Approved Method: IES Spatial Daylight Autonomy (sDA) and Annual Sunlight Exposure (ASE). New York, 2012.

KONSTANTZOS, I.; TZEMPELIKOS, A.; CHAN, Y. Experimental and simulation analysis of daylight glare probability in offices with dynamic window shades. Building and Environment. v. 87, p. 244-254, mai. 2015.

doi:https://doi.org/10.1016/j.buildenv.2015.02.007

MARCONDES, Mônica Pereira. Soluções projetuais de fachadas para edifícios de escritórios com ventilação natural em São Paulo. 2010. Tese (Doutorado em Tecnologia da Arquitetura) - Faculdade de Arquitetura e Urbanismo, Universidade de São Paulo, São Paulo, 2010. doi:https://doi.org/10.11606/T.16.2010.tde-10112010-102255.

MOON, P.; SPENCER, D. E. Illumination from a non-uniform sky. The Illuminating Engineer, v. 37, p. 707-726, 1942.

MORAES, L. N., PEREIRA, F. O. R. Um método simplificado para avaliação do desempenho dinâmico da iluminação natural. In: ENCONTRO NACIONAL DE CONFORTO NO AMBIENTE CONSTRUÍDO, 11, ENCONTRO LATINO AMERICANO DE CONFORTO NO AMBIENTE CONSTRUÍDO, 7, 2011, Buzios. Anais... Porto Alegre: ANTAC, 2011. p. 1-10.

NABIL, A.; MARDALJEVIC, J. Useful daylight illuminance: a new paradigm for assessing daylight in buildings. Lighting Res. Technol. v. 37, n. 1, p. 41-59, 2005. doi:https://doi.org/10.1191/1365782805li128oa

NABIL, A.; MARDALJEVIC, J. Useful daylight illuminances: a replacement for daylight factors. Energy and Buildings. v. 38, n. 7, p. 905-913, 2006. doi:https://doi.org/10.1016/j.enbuild.2006.03.013

PEREIRA, Daniela Cardoso Laudares. Iluminação natural em edifícios de escritórios: metodologia para avaliação do desempenho luminoso. 2017. Tese (Doutorado em Tecnologia da Arquitetura) - Faculdade de Arquitetura e Urbanismo, Universidade de São Paulo, São Paulo, 2017. Disponível em: <http://www.teses.usp.br/teses/disponiveis/16/16132/tde-22062017155747/>. Acesso em: 2018-05-10.

PEREIRA, F.O.R.; FONSECA, R.W.; MORAES, L.N.; RENDÓN, L.G.; SOBREIRA, A.S. Iluminação natural: comparação entre percepção visual e medidas dinâmicas de avaliação. In: ENCONTRO NACIONAL TECNOLOGIA NO AMBIENTE CONSTRUÍDO, 14, 2012, Juiz de Fora. Anais... Porto Alegre: ANTAC, 2012.

REINHART, C. F. Effects of interior design on the daylight availability in open plan offices. In: CONFERENCE OF THE AMERICAN COUNCIL FOR AN ENERGY-EFFICIENT ECONOMY SUMMER STUDIES ON ENERGY EFFICIENCY IN BUILDINGS, 2002, Pacific Grove. Proceedings ... Pacific Grove: ACEEE, 2002. p.3309-3322. Disponível em: $<$ https://www.eceee.org/library/conference_proceedings/ACEEE_buildings/2002/Panel_3/p3_24/>. Acesso em: Acesso em: 2018$05-10$.

REINHART, C. F.; WALKENHORST, O. Validation of dynamic RADIANCE-based daylight simulations for a test office with external blinds. Energy and Buildings, v. 33, n. 7, p. 683-697, 2001. doi:https://doi.org/10.1016/S0378-7788(01)00058-5

REINHART, C. F.; MARDALJEVIC, J.; ROGERS, Z. Dynamic daylight performance metrics for sustainable building design. LEUKOS, v.3, n. 1, p. 7-31, 2006. doi:https://doi.org/10.1582/LEUKOS.2006.03.01.001

ROCHA, A. A.; PEREIRA, F. O. R. Avaliação do consumo de energia de edificações considerando a luz natural e sistemas de controle através de simulação computacional integrada. In: ENCONTRO NACIONAL DE CONFORTO NO AMBIENTE 
CONSTRUÍDO, 11, ENCONTRO LATINO AMERICANO DE CONFORTO NO AMBIENTE CONSTRUÍDO, 7, 2011, Buzios. Anais... Porto Alegre: ANTAC, 2011.

ROCHE, L. Summertime performance of an automated lighting and blinds control system. Lighting Research and Technology, v. 34, n. 1, p. 11-25, 2002. doi:https://doi.org/10.1191/1365782802li026oa

SCHULER, M. Building simulation in application: Developing concepts for low energy buildings through a co-operation between architect and engineer. In: INTERNATIONALCONFERENCE ON SOLAR ENERGY BUILDINGS, 1995, Harare. Proceedings... Harare: ISES, 1995.

SHEN, H., TZEMPELIKOS, A. Daylighting and energy analysis of private offices with automated interior roller shades. Solar Energy. v. 86, N. 2, p. 681-704, fev. 2012. doi:https://doi.org/10.1016/j.solener.2011.11.016

SILVA, V. A influência dos protetores solares no comportamento da luz natural em edifícios de escritórios. 2011.115 f. Dissertação (Mestrado) - Universidade de Brasília, Brasília, 2011.

UMAKOSHI, Erica Mitie. Avaliação de desempenho ambiental e arquitetura paramétrica generativa para o projeto do edifício alto. 2014. Tese (Doutorado em Tecnologia da Arquitetura) - Faculdade de Arquitetura e Urbanismo, Universidade de São Paulo, São Paulo, 2014. doi:https://doi.org/10.11606/T.16.2014.tde-02072014-114503.

WYMELENBERG, K., INANICI, M. A Critical Investigation of Common Lighting Design Metrics for Predicting Human Visual Comfort in Offices with Daylight. LEUKOS. v. 10, n. 3, p. 145-164, 2014. doi:https://doi.org/10.1080/15502724.2014.881720

\section{${ }^{1}$ Mônica Pereira Marcondes Cavaleri}

Arquiteta-Urbanista pela Faculdade de Arquitetura e Urbanismo da Universidade de São Paulo, FAUUSP. Mestre pela Architectural Association School of Architecture, AA, Londres. Doutora pela Faculdade de Arquitetura e Urbanismo da Universidade de São Paulo, Bolsista de Pós-Doutorado da CAPES, na FAUUSP. Endereço Postal: Rua do Lago, 876, Cidade Universitária, CEP: 05508-080, São Paulo, SP, Brasil.

\section{${ }^{2}$ Guilherme Reis Muri Cunha}

Aluno do Curso de Graduação da Faculdade de Arquitetura e Urbanismo da Universidade de São Paulo, FAUUSP. Endereço Postal: Rua do Lago, 876, Cidade Universitária, CEP: 05508-080, São Paulo, SP, Brasil.

\section{Joana Carla Soares Gonçalves}

Arquiteta-Urbanista pela Universidade Federal do Rio de Janeiro. Professora Associada da Faculdade de Arquitetura e Urbanismo da Universidade de São Paulo, FAUUSP. Endereço Postal: Rua do Lago, 876, Cidade Universitária, CEP: 05508-080, São Paulo, SP, Brasil 